\title{
Pain: A culturally informed experience
}

\author{
David Ng BArtsSc
}

$I_{w}^{w}$ was raised in North America - a culture and society in which the education emphasizes knowledge about science, its methods and its principles. The scientific method of understanding, coupled with the rudimentary knowledge that I was taught in high school biology, resulted in my conceptualization of pain as an objective truth. Pain, as I believed for a long time, was a bodily sensation with an expression that was more or less universal; to me, pain was simply the sensation that the brain experiences as a response to noxious stimuli. The pain sensation protects us from things that can hurt us; it is a warning sign that something in us is physically amiss. Thus, everybody physically reacts to the touch of a flame or experiences abdominal pain when there is appendicitis. Even now, in medical school, the pain education that I have received so far has only involved the physiology or mechanics of pain. Pain, as a physiological condition, operates independent of cultural context. However, in considering the experience of pain that my grandmother has endured, I realize that pain is much more than a mechanical bodily sensation effected by the nervous system in response to stimulus. Pain is a human experience, and as such, it is highly individualized and subjective. The proper diagnosis, care and treatment of pain necessitate a holistic understanding of pain, its physiology and its context (1).

Two and a half years ago, my grandmother suddenly contracted acute liver pain that progressed to include splenic pain. Although she was 65 years old, it was quite a shock to the family that the matriarch had fallen ill with acute physical pain. My grandmother had been a flagship of strength and resolve in our family. Although she was born to a poor rural family in China, she had raised and supported seven children to be successful professionals and entrepreneurs in Hong Kong and Canada. We knew that the pain must have been serious because my grandmother never complained of pain, she always accepted and endured it with firm stoicism. When my own mother complained of the hellish pain that had accompanied my entrance into the world, my grandmother would embark on a diatribe about how she carried my mother to term while working the rice paddies everyday. My grandmother eventually delivered my mother one evening and returned to work in the fields the next morning - all without an epidural!

The onset of my grandmother's pain was quite sudden. Over the course of six months, what had begun as occasional flaring stabs of liver pain had progressed to severe chronic pain of the liver and a dull, throbbing pain in her spleen. The consequent impact of this pain on her life was very significant. The pain in her liver resulted in a decrease in appetite, and thus she began to lose weight, energy and vitality. My grandmother does not speak English, and having only recently moved from Hong Kong to live with my uncle, she had a limited social network with whom she would play mah-jong and do Tai-Chi. Her greatest source of esteem upon living in Canada was to do housework and help take care of her grandchild Aiden, my cousin.

\footnotetext{
This essay received the Dr Earl Russell Prize, sponsored by Janssen-Ortho Inc, for a medical student in his or her first, second or third year at the University of Western Ontario, London, Ontario. 
Unfortunately, the pain in her liver severely incapacitated her. She could no longer do the housework or take care of Aiden. Furthermore, whether it was pride of not wanting to be seen in pain, or out of the sheer pain itself, she became withdrawn and would no longer participate in mah-jong or Tai-Chi. When I talk with my grandmother about this traumatic time, her tone is quite sad. The liver pain had given her 'anomie', an experience of life bereft of meaning.

During this difficult time, my grandmother began having regularly scheduled appointments with Dr Yick (not his real name), a Canadian-born Chinese man, our family physician. Dr Yick found my grandmother's pain presentation to be very unusual. Upon inspection, there was no swelling or any other physical sign pertaining to liver or splenic pain. My grandmother simply described the pain as hot stabbing in the liver and dull-throbbing in the spleen. Over the next couple of months, Dr Yick sent my grandmother for a battery of blood tests and even an ultrasound. All the tests came back negative; her upper abdominal pain was 'idiopathic'. She did not have hemolytic disease, signs of cancer, gall bladder stone or duodenal ulcer. Furthermore, the Tylenol \#2 (McNeil Healthcare, Canada) that Dr Yick prescribed did nothing to alleviate my grandmother's pain. In fact, she only became nauseated and dizzy - common side effects of the codeine in the Tylenol \#2.

Dr Yick's diagnosis and treatment failures were very frustrating to my grandmother and the family. The final tentative diagnosis of 'psychogenic' pain was confusing and inadequate. Dr Yick could not establish any objective physical signs or etiology for my grandmother's liver pain. There was no inflammation, all the liver enzyme tests were negative and the medication was useless. Yet, clearly my grandmother was very ill due to pain. The pain severely limited her daily social and physical functioning, and her condition continued to deteriorate rapidly. Our family was very confused. Was our grandmother physically ill? Or was 'psychogenic' pain just a pain that was in our grandmother's head? We revere our grandmother, and the notion that she was becoming senile with pain was unacceptable. However, modern medical science as represented by Dr Yick could provide no other answer. My grandmother was very angry and in despair. She resented that Dr Yick could not validate her pain with a medical condition and give her appropriate treatment. She felt misunderstood and began to question her own coherence. Finally, as a result of her life bereft of meaning and the inability of Dr Yick to help, my grandmother decided to go back to Hong Kong to stay with other relatives and sought aid from the traditional Chinese medicine clinic she frequented when in Hong Kong.

I must acknowledge that I am not aware of the particular details regarding the traditional Chinese medical clinic that my grandmother went to. I do not know whether they practice Western medicine combined with certain Eastern practices, or whether they concentrate solely on herbs and acupuncture, or any permutation in between. However, upon receiving several consultations, counselling sessions and a herbal regimen, my grandmother's condition improved remarkably in Hong Kong. Although, the pain did not completely go away, she could perform physical activities, and as relatives in Hong Kong reported, she was in good spirits. Three months later, my grandmother returned to Canada, and on recommendation from the Chinese doctor, she moved in with my family rather than my uncle's family. My uncle came to visit my grandmother often, and over time her liver and splenic pain actually went away.

My family was quite relieved at my grandmother's improved condition, and most of us simply assumed that the trip back to Hong Kong and perhaps the herbal remedies were responsible. To further mystify her sudden amelioration, my grandmother, to this day, declines to speculate or explain her sudden improvement. She just says that she is happy and enjoys the way that things are now. It was not until very recently that news had travelled through the trans-pacific grapevine that my grandmother had in fact suffered from 'depression', expressed as pain. When my mother explained what my grandmother had experienced to me, to my surprise, my mother ended up describing the concept of cultural somatization.

It is known that, among traditional Chinese, the liver is an organ symbolic of anger, and the spleen as an organ symbolic of sorrow. In the Chinese language, there is a colloquial term that literally says, "liver attacks the spleen", thus meaning pent up anger turned to sorrow. Because it is not customary and even stigma-susceptible to express disturbances of psychological states in Chinese culture, somatization, the expression of physical symptoms, is a culturally appropriate method with which to communicate psychological distress. As I discovered, this phenomenon is consistent with my grandmother's recent history.

In recent years, my grandmother has led an emotionally tumultuous life. Three years ago, when my grandfather died, my grandmother immigrated from China to Canada to live with her first-born son. This custom of elderly people moving in with their first-born son is culturally accepted, if not expected, among many Chinese in China. My uncle loves my grandmother very much and was quite happy to be able to fulfill his role as my grandmother's primary caregiver. However, although the tension between mothers and daughters-in-law have been significantly caricatured in our society, the animosity between my grandmother and her daughter-in-law was epic to say the least. As an IrishCanadian woman from a family that has been well acculturated to the concept of independent living, my aunt did not understand why my grandmother was living in her household. Often, the two women of the house would fight over the way that the housework was done. They would compete to do the work, and compete for the attention of my uncle, each disparaging the other woman of the house. Although my grandmother will not speculate on the specifics of her treatment with the traditional doctor, when I asked her about what she felt during this time, she recalls feeling very angry and confused. My grandfather had just passed away and she loved him very much. It was at this 
time that she had decided to move in with my uncle in Canada, knowing that she could always count on him. However, Canada was a very foreign place to her. Although she admired the serenity, she was used to the hustle and bustle of Hong Kong. Furthermore, she could not speak English and thus she was socially isolated, both in public and at home. She was frustrated that she could not be a part of the conversation between her son and her daughter-in-law. Soon, she found that she did not like the daughter-in-law; they could not communicate and they disagreed on how the housework should be done and how Aiden should be cared for. My grandmother felt unwanted by the daughter-in-law and was angry. Eventually, her anger turned to sorrow because her son loved both of them, and in defending his mother he was fighting with his wife and thus becoming very unhappy. She felt responsible for his unhappiness. Finally, when Dr Yick could not treat her and made her feel as if she was 'crazy', she wanted to leave Canada.

In reflecting upon my grandmother's pain experience, I am intrigued at how well the concept of clinical pain illustrates the importance of developing a patient-centred, holistic approach to examining the patient. The proper diagnosis and treatment of my grandmother's liver pain were made simple by a traditional Chinese doctor because this doctor was culturally attuned to my grandmother's specific pain presentation. Thus, the Chinese doctor was able to elicit the feelings surrounding my grandmother's pain, and to counsel and effectively cure her. At the same time, I feel that it is not entirely inexcusable that Dr Yick was unable to identify cultural somatization as the cause of my grandmother's pain because he is a Canadian-born Chinese person, and like myself, he was unaware that the liver was symbolic for anger in our traditional culture. Nevertheless, I do believe that if Dr Yick had conducted a more thorough history on my grandmother, perhaps he could have come to understand it as a source of distress, if not for the pain itself. Dr Yick was commendable in exploring every route to find the etiology of the pain sensation. Unfortunately, the diagnosis of psychogenic pain did not reflect my grandmother's pain, it did not encourage a deeper look into the cultural context, where the solution may lie, as it did in the case of my grandmother.

\section{REFERENCE}

1. Helman C. Culture Health, and Illness. Oxford: Butterworth Heineman, 2000. 


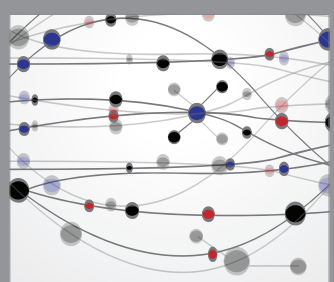

The Scientific World Journal
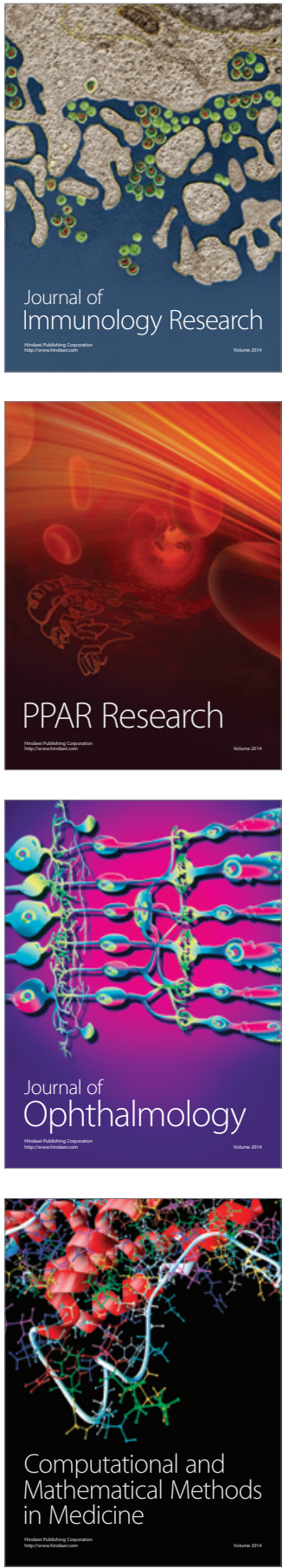

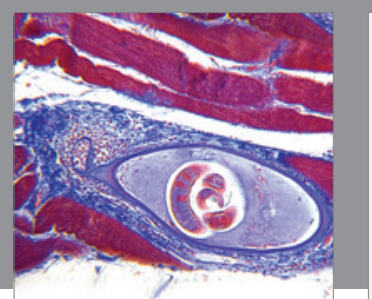

Gastroenterology Research and Practice

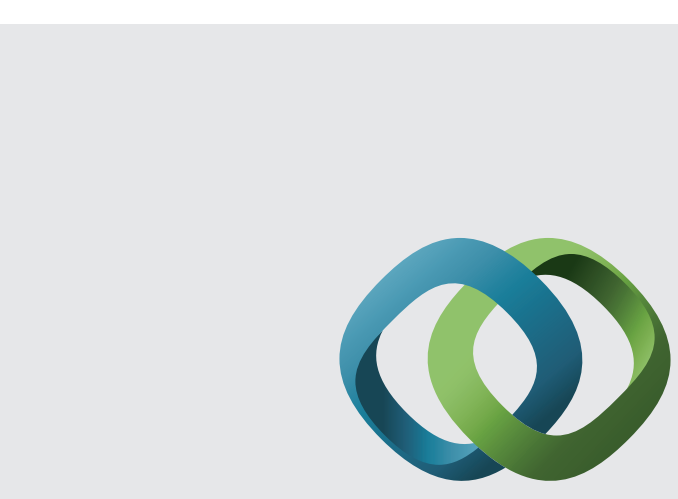

\section{Hindawi}

Submit your manuscripts at

http://www.hindawi.com
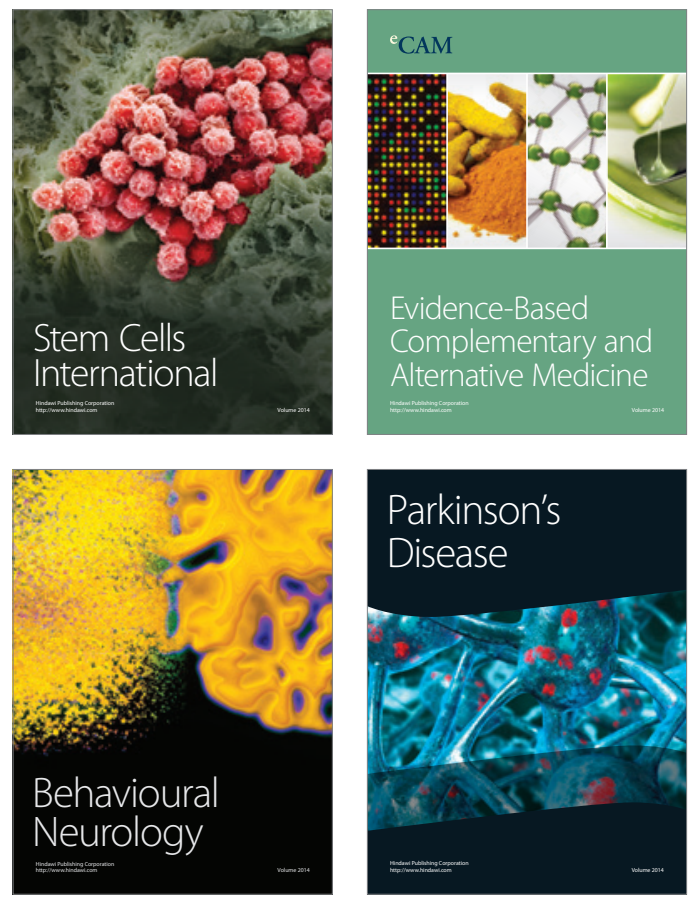
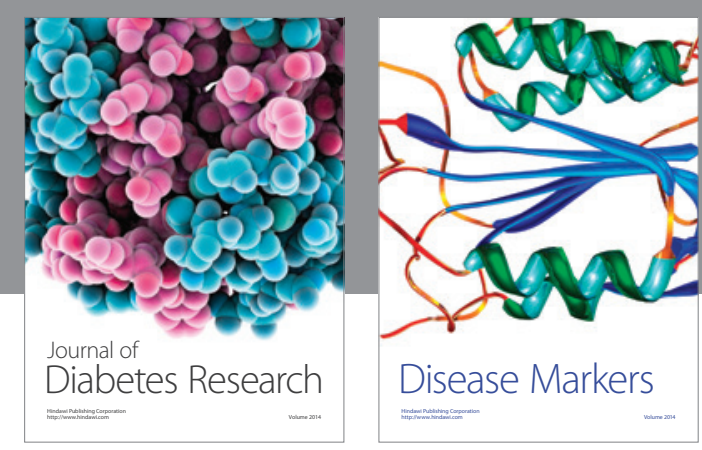

Disease Markers
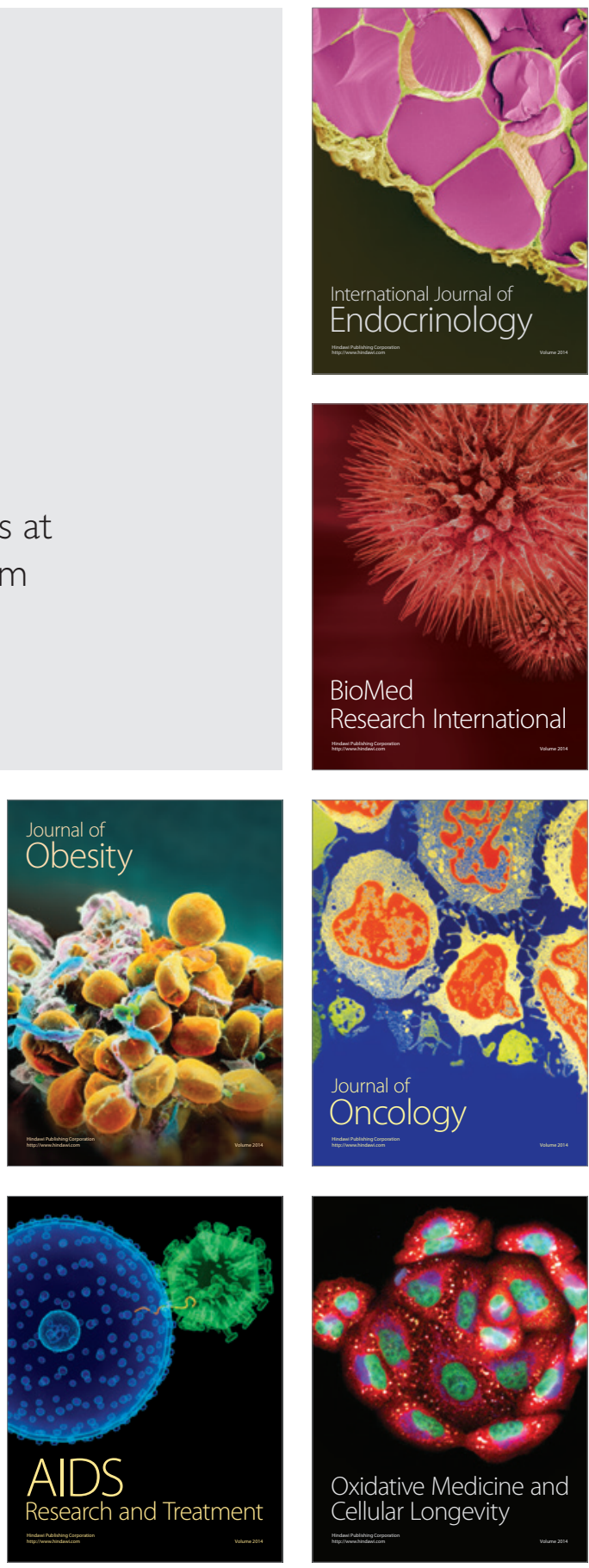